\title{
Molecular cloning and expression of bovine nucleoplasmin 2 (NPM2): a maternal effect gene regulated by miR-181a
}

Brandon M Lingenfelter ${ }^{1,5}$, Swamy K Tripurani ${ }^{1}$, Jyothsna Tejomurtula ${ }^{1}$, George W Smith ${ }^{2,3,4}$ and Jianbo Yao ${ }^{1 *}$

\begin{abstract}
Background: Nucleoplasmin 2 (NPM2) is an oocyte-specific nuclear protein essential for nuclear and nucleolar organization and early embryonic development. The aims of this study were to clone the bovine NPM2 gene, determine its temporal expression during oocyte development and early embryogenesis, and evaluate the potential role of miRNA-181a in regulation of its expression.
\end{abstract}

Methods: A 329 bp cDNA fragment was amplified from bovine fetal ovary using primers designed based on the conserved regions of the human and mouse NPM2 CDNA sequences. RACE experiments were performed to obtain the $5^{\prime}$ and $3^{\prime}$ ends of the bovine NPM2 cDNA. Real time PCR and Western blot analysis were used to examine the expression of bovine NPM2 in oocytes and early embryos. Co-expression of bovine NPM2 and miRNA-181a in Hela cells was performed to determine if expression of bovine NPM2 is regulated by miRNA-181a.

Results: The bovine NPM2 CDNA is 851 bp in length encoding a protein of 200 amino acids. The protein contains the conserved bipartite nuclear localization sequence and shows $53 \%$ and $62 \%$ identity with mouse and human NPM2, respectively. Expression of bovine NPM2 mRNA is restricted to ovaries. NPM2 mRNA is abundant in GV and MII stage oocytes, decreases in early cleavage stage embryos, and barely detectable in morula and blastocyst stage embryos. Similarly, expression of NPM2 protein is high in oocytes and early embryos but extremely low in blastocysts. The abundance of NPM2 mRNA is significantly lower in oocytes isolated from persistent versus growing dominant follicles $(P<0.05)$. A miR-181a binding site in the $3^{\prime} U T R$ of the NPM2 transcript was identified.

Transfection experiments showed that bovine NPM2 protein expression is reduced in Hela cells expressing miR181a compared to control cells without miR-181a, indicating that translation of NPM2 is repressed by miR-181a.

Conclusions: Our data suggest that expression of bovine NPM2 is temporally regulated during early embryogenesis and miR-181a may play a role in its regulation.

\section{Background}

Maternal mRNAs that accumulate in the oocyte during oogenesis play important roles during initial stages of embryonic development, before activation of the embryonic genome [1]. Some of the maternal transcripts are oocyte-specific and known as maternal effect genes which are required for the early cleavage events post fertilization $[2,3]$. Examples of maternal effect genes that have been identified in mice include maternal antigen

\footnotetext{
* Correspondence: jianbo.yao@mail.wvu.edu

'Laboratory of Animal Biotechnology and Genomics, Division of Animal and Nutritional Sciences, West Virginia University, Morgantown, WV 26506, USA Full list of author information is available at the end of the article
}

that embryos require (Mater) [4], zygote arrest 1 (Zar1) [5] and nucleoplasmin 2 (Npm2) [6].

To ensure formation of a diploid genome after fertilization, maternal and paternal DNA must undergo remodeling. NPM2, an oocyte-specific nuclear factor, plays an important role in this process. In Xenopus laevis, nucleoplasmin (NPM) decondenses sperm DNA after its entry into the oocyte $[7,8]$. Knockout of NPM2 in mice reduced initial cleavage of embryos and impaired development to the 2-cell stage, and resulted in fragmentation and asynchrony of further cleavage and death by $50 \mathrm{hr}$ post-fertilization [6]. Microinjection of NPM into bovine oocytes after nuclear transfer resulted in increased viability of embryos and higher rate of

\section{Biomed Central}


pregnancy [9], suggesting a role for NPM in facilitating reprogramming of the somatic nucleus.

Degradation of maternal transcripts allows normal embryonic development $[10,11]$. Multiple mechanisms for maternal RNA degradation exist [12] including the actions of microRNAs (miRNAs). MicroRNAs downregulate gene expression by binding to known miRNAtarget sites on mRNA in the 3' untranslated region (3'UTR) [13]. Knockout of Dicer, an enzyme required for the production of mature miRNAs, results in increased embryonic death in mice $[14,15]$ and abnormal development in zebrafish [16]. A particular miRNA, miR-430, has been showed to target several hundred maternal mRNAs in zebrafish [17].

In domestic animals, major activation of the embryonic genome takes place later as compared to rodents (e.g. 8-16-cell stage in cattle vs. 2-cell stage in mouse) suggesting potential species differences in mechanisms and mediators of the maternal-to-embryonic transition. To date, bovine orthologues of mouse Mater and Zar1 have been cloned and their expression profiles during oocyte maturation and early embryogenesis characterized [18-20]. Recently, two novel oocyte-specific genes, $J Y-1$ and KPNA7, have been discovered in cattle and their roles in regulating early embryonic development demonstrated $[21,22]$. Furthermore, the mechanisms responsible for characteristic temporal expression pattern of products of specific maternal effect genes during early embryogenesis are not completely understood. In this study, we report the cloning of bovine NPM2, its mRNA and protein expression during oocyte maturation and early embryonic development and the potential role of miR-181a in regulation of its expression.

\section{Methods}

\section{Tissue collection and RNA isolation}

Bovine tissue samples including adult liver, lung, thymus, kidney, muscle, heart, spleen, cortex (brain), pituitary, adrenal, testis, ovary, and fetal testis and ovaries, were collected at a local slaughterhouse. All samples were frozen in liquid nitrogen and stored at $-80^{\circ} \mathrm{C}$ until RNA isolation. Total RNA was isolated from these tissues using TRIzol reagent (Invitrogen, Carlsbad, CA) and treated with DNase (Promega, Madison, WI) according to manufacturer's protocols.

\section{RT-PCR analysis of bovine NPM2 mRNA expression}

Total RNA from various bovine tissues was used to generate cDNA using oligo $(\mathrm{dT})_{18}$ primer and Superscript III reverse transcriptase (Invitrogen, Carlsbad, CA). Negative control reactions (without the enzyme) were carried out to confirm the absence of genomic DNA contamination. First-strand cDNA was used as a template for PCR amplification of a 329 bp fragment using bovine NPM2 gene-specific primers (Additional file 1, Table S1). The PCR was performed using 35 cycles of $94^{\circ} \mathrm{C}$ for $30 \mathrm{sec}, 59^{\circ} \mathrm{C}$ for $45 \mathrm{sec}$ and $72^{\circ} \mathrm{C}$ for $30 \mathrm{sec}$, and a final extension at $72^{\circ} \mathrm{C}$ for $10 \mathrm{~min}$. Bovine ribosomal protein L19 (RPL19) gene was used as a positive control.

\section{Cloning of bovine NPM2 CDNA by PCR and RACE}

PCR primers were designed based on conserved regions of human (NM_182795) and mouse (NM_181345) NPM2 sequences to amplify a 329 bp cDNA fragment from a fetal ovary sample (230 days of gestation). The product was cloned using TOPO ${ }^{\circledR}$ TA cloning kit (Invitrogen, Carlsbad, CA) and sequenced. Primers for $5^{\prime}$ and 3'RACE were designed based on the obtained bovine NPM2 cDNA sequence (Additional file 1, Table S1). RACE experiments were performed to obtain the 5 ' and 3' ends of bovine NPM2 cDNA using the second generation 5'/3'RACE kit (Roche Diagnostics, Indianapolis, IN) following the manufacturer's protocol. Total RNA from bovine fetal ovary was used to generate cDNA with either a gene-specific primer (5'RACE) or an oligo $\mathrm{d}(\mathrm{T})$-anchor primer (3'RACE) followed by nested PCR using gene-specific primers in conjunction with $d(T)$ anchored primers provided in the kit. The specific PCR products were cloned using the $\mathrm{TOPO}^{\circledR}$ TA cloning kit (Invitrogen, Carlsbad, CA). The RACE products were sequenced at the University of Illinois Core DNA Sequencing Facility (Urbana, IL).

\section{Quantitative real time PCR analysis}

Expression of bovine NPM2 mRNA during oocyte maturation and early embryonic development was determined by real time PCR as described previously [23] using primers listed in Additional file 1, Table S1. GV and MII stage oocytes, pronuclear, 2-cell, 4-cell, 8-cell, 16 -cell, morula and blastocyst stage embryos $(\mathrm{n}=5$ pools of 10 each) were obtained by in vitro fertilization of abattoir derived oocytes as described [23]. Total RNA from oocytes and embryos was isolated using the RNAqueous ${ }^{\circledR}$-Micro kit (Ambion Inc., Austin, TX). Spiked green fluorescent protein (GFP) synthetic RNA was used as an exogenous control to account for variations in RNA recovery and efficiency of cDNA synthesis between samples.

Quantitative real time PCR analysis of bovine NPM2 mRNA expression in oocytes from growing and persistent dominant follicles was performed as described previously [24]. Oocytes from growing (day 6) and persistent follicles $($ day 13 , estrus $=$ day 0 ) were used in this analysis. Total RNA isolated from individual oocytes was subjected to linear amplification before real time PCR assay. Bovine HIST2H2AA4 gene (BF076713) was used as an endogenous control for data normalization as 
expression of this gene does not differ in oocytes from the two types of follicles [24]. Primers for this gene are listed in Additional file 1, Table S1.

Quantitative real time PCR analysis of miR-181a expression in oocytes and early stage embryos was performed as described [25]. miR-125b was used as an endogenous control to normalize the target miRNA because this miRNA is expressed consistently in preimplantation mouse embryos [26].

\section{Western blot analysis}

Western blot analysis of bovine NPM2 protein expression in oocytes and early embryos was performed as previously described [22]. The oocyte and embryo samples (50 oocytes/embryos each lane) were purchased from Bomed Inc. (Madison, WI). The primary antibody (anti-bovine NPM2) was prepared commercially by GenScript Corporation (Piscataway, NJ). It was generated by immunizing rabbits with a 15 -amino acid synthetic peptide (ERPTWTFKPQKVGKC, amino acid position 26-39) of bovine NPM2 protein. Unpurified antiserum from the third bleed was used in the study.

\section{Preparation of expression constructs}

The plasmid expressing bovine NPM2 was constructed by cloning of the full length bovine NPM 2 cDNA into pcDNA3.1 expression vector (Invitrogen, Carlsbad, CA). PCR primers (Additional file 1, Table S1) containing BamHI (forward) and XhoI (reverse) restriction sites were designed to amplify the full length bovine NPM2 cDNA using a fetal ovary cDNA sample (230 days of gestation). The amplified PCR product was cloned using TOPO $^{\circledR}$ TA cloning kit (Invitrogen, Carlsbad, CA) followed by subcloning into the BamHI and XhoI sites of pcDNA3.1. The plasmid designed to express the bovine miR-181a was prepared by cloning a 262 bp genomic fragment containing the pre-miR-181a into pcDNA3.1. Primers containing BamHI (forward) and PmeI (reverse) restriction sites (Additional file 1, Table S1) were used to amplify the 262 bp DNA fragment from kidney genomic DNA. Following TA cloning the product was cloned into the BamHI and PmeI sites of pcDNA3.1. Both constructs were sequenced to ensure that no mutations were introduced during PCR amplification.

\section{Cell culture and transfection experiments}

HeLa cells from ATCC (Manassas, VA) were grown at $37^{\circ} \mathrm{C}$ in a humidified incubator containing $5 \% \mathrm{CO}_{2}$ in Dulbecco's modified Eagle's medium (DMEM; Invitrogen, Carlsbad, CA) supplemented with 10\% fetal bovine serum (FBS) and 1\% penicillin-streptomycin. Stable HeLa cells expressing bovine miR-181a was generated by transfecting the cells with miRNA-181a plasmid followed by selection in G418. Transfection experiments $(n=5)$ were conducted using 6-well culture dishes. HeLa cells were passed at least 12 hours prior to all transfection experiments. HeLa cells expressing bovine miR-181a were transfected with NPM2 plasmid $(1 \mu \mathrm{g})$ or pcDNA3.1 vector $(1 \mu \mathrm{g})$ using FuGene ${ }^{\circledR} 6$ transfection reagent (Roche Applied Science, Indianapolis, IN) according to the manufacturer's instructions. Control Hela cells not expressing bovine miR181a were also transfected with NPM2 plasmid or pcDNA3.1 vector. Twenty-four hours posttransfection, all cells were harvested by trypsinization. Cell pellets were lysed in cell lysis buffer $(100 \mathrm{mM}$ sodium $\beta$-glycerophosphate, $20 \mathrm{mM}$ HEPES, $15 \mathrm{mM}$ $\mathrm{MgCl}_{2}, 5 \mathrm{mM}$ EGTA, $100 \mathrm{mM}$ 4-amidinophenylmethylsulfonyl fluoride, $3 \mathrm{mg} / \mathrm{ml}$ leupeptin, and $10 \mathrm{mg} / \mathrm{ml}$ aprotinin, $\mathrm{pH}$ 7.5) followed by sonication using an Ultrasonic Homogenizer (BioLogics, Manassas, VA). Western blot analysis of NPM2 protein expression in these cells was performed using anti-bovine NPM2 antibody as described above. Detection of GAPDH (protein loading control) was performed using anti-GAPDH antibody (Ambion, Austin, TX). Density of the protein bands was determined using a densitometer and NPM2 protein expression was normalized with GAPDH.

\section{Statistics}

Differences in expression of NPM2 mRNA and protein and miRNA-181a between samples were analyzed by GLM procedures of SAS with LS means (SAS 9.1.3, SAS Institute Inc., Cary, NC). Different letters indicate significant differences $(P<0.05)$.

\section{Results and discussion}

cDNA cloning and tissue distribution of bovine NPM2

The complete cDNA sequence (851 bp) for bovine NPM2 was obtained by assembly of the sequences from the PCR and RACE fragments (Figure 1A). The sequence has been deposited in GenBank (accession number: FJ769182). BLAST search of the bovine reference genome sequence in the NCBI database using the bovine NPM2 $c D N A$ did not find the corresponding gene sequence. However, a previous bovine chromosome 8 genomic contig sequence (NW_932049) in GenBank database contains the NPM2 gene which spans $\sim 14.6 \mathrm{~kb}$. Alignment of the cDNA with the genomic sequence using the NCBI Splign program [27] revealed that the bovine NPM2 gene contains 9 exons separated by 8 introns (Figure 1B). Visual inspection of the promoter region identified 2 putative E-boxes (cacctg) located approximately $200 \mathrm{bp}$ upstream of the predicted transcription start site (data not shown). Such elements are known to be responsible for oocyte-specific gene expression $[28,29]$.

The bovine NPM2 cDNA encodes a protein of 200 amino acids. Analysis of the predicted NPM2 protein 


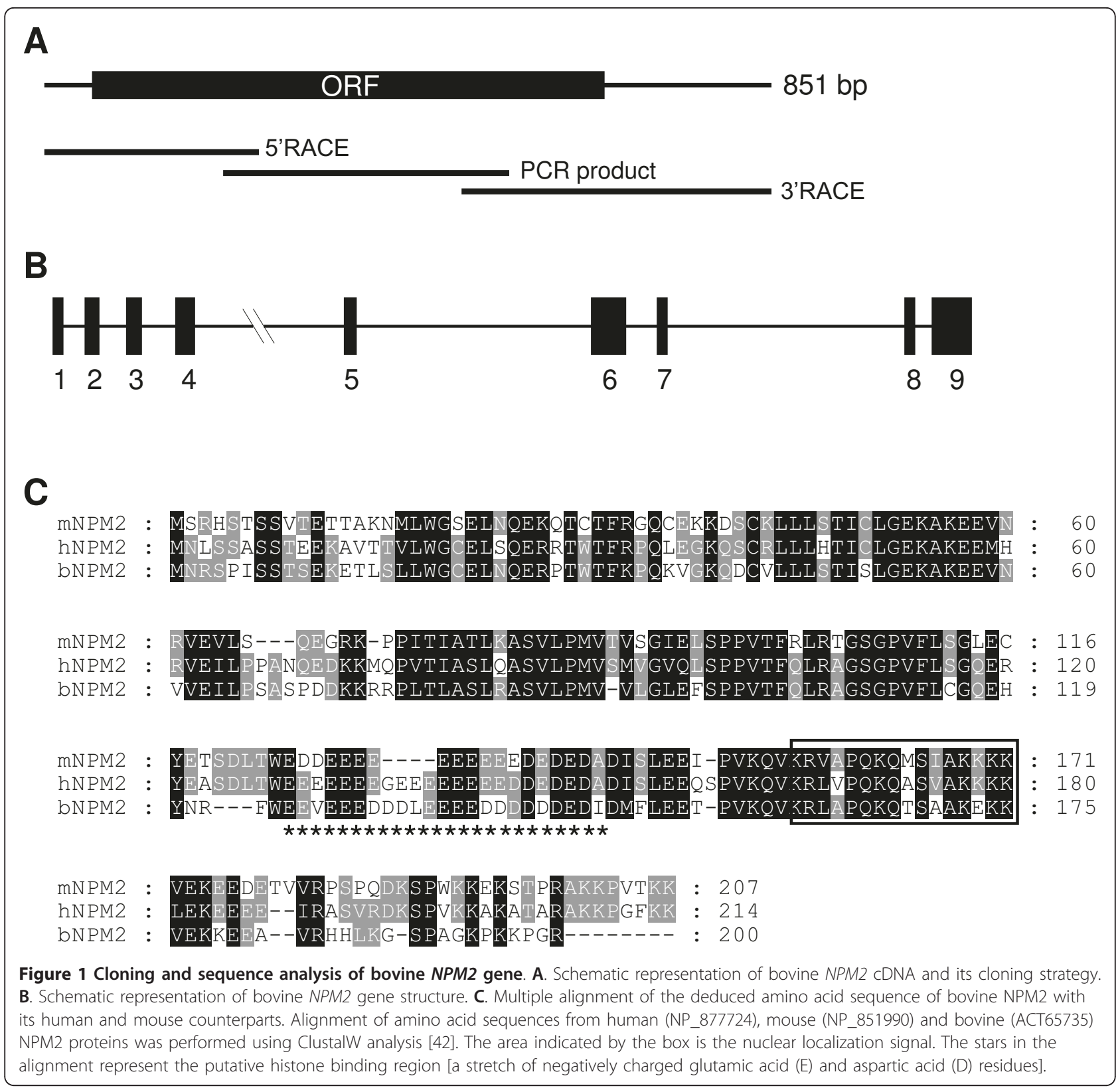

sequence revealed that it contains a conserved bipartite nuclear localization signal (KRLAPQKQTSAAKEKK), and a series of glutamic and aspartic residues (E and D) implicated in binding histones and protamines (Figure $1 \mathrm{C})$. The protein shows $53 \%$ and $62 \%$ amino acid sequence identity with the mouse and human NPM2, respectively (Figure $1 \mathrm{C}$ ).

To determine the tissue distribution of the bovine NPM2 gene, RT-PCR was performed using RNA samples isolated from multiple bovine tissues. As shown in Figure 2, expression of bovine NPM2 mRNA was restricted to adult and fetal ovaries, which is consistent with the result of Northern blot analysis to detect mouse Npm2 expression [6].

Expression of bovine NPM2 mRNA and protein in oocytes and early embryos

Expression of NPM2 mRNA in bovine oocytes (GV and MII stage) and early embryos (pronuclear, 2-cell, 4-cell, 8-cell, 16-cell, morula and blastocyst stage) was investigated by quantitative real time PCR. The results indicate that NPM2 mRNA is most abundant in GV and MII stage oocytes relative to early embryos. The abundance of mRNA for NPM2 is decreased in embryos at 

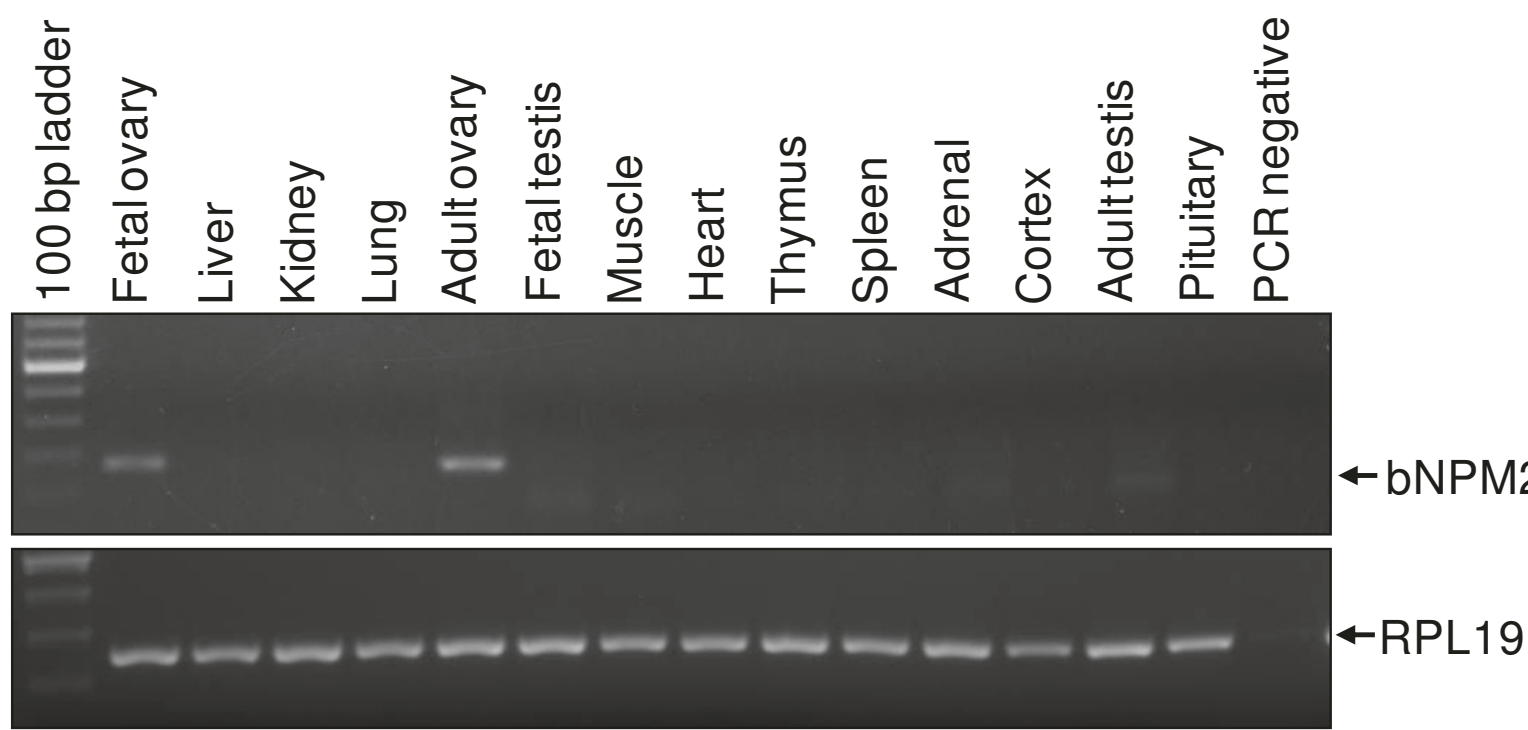

Figure 2 Tissue distribution of bovine NPM2 mRNA. Expression of NPM2 mRNA in various bovine tissues including liver, lung, thymus, kidney, muscle, heart, spleen, cortex, pituitary, adrenal, testis, ovary, fetal testis and fetal ovary was determined by RT-PCR analysis. Bovine ribosomal protein L19 (RPL19) was used as a positive control for RNA quality and RT.

pronuclear and 2-cell stage, is further decreased from 4-cell to 16-cell stages, reaching a level that is barely detectable in morula and blastocyst stage embryos (Figure 3A; $\mathrm{P}<0.05$ ). Abundance of bovine NPM2 protein in GV and MII stage oocytes as well as in 2-cell, 16-cell and blastocyst stage embryos was evaluated by Western blot analysis. As shown in Figure 3B, the protein is abundant in GV and MII stage oocytes and remains fairly abundant in 2 -cell and 16 -cell stage embryos but drops sharply by the blastocyst stage. The immunoreactive protein band for bovine NPM2 protein is approximately $30 \mathrm{kDa}$ which is similar to the size of mouse NPM2 protein (32 kDa) [30] but larger than predicted size of $\sim 22 \mathrm{kDa}$. Sumoylation of the protein could be a cause for this discrepancy as the protein contains a sumoylation consensus motif ( $\Psi K X E)$. The expression pattern of bovine NPM2 mRNA and protein during early embryogenesis is very similar to a number

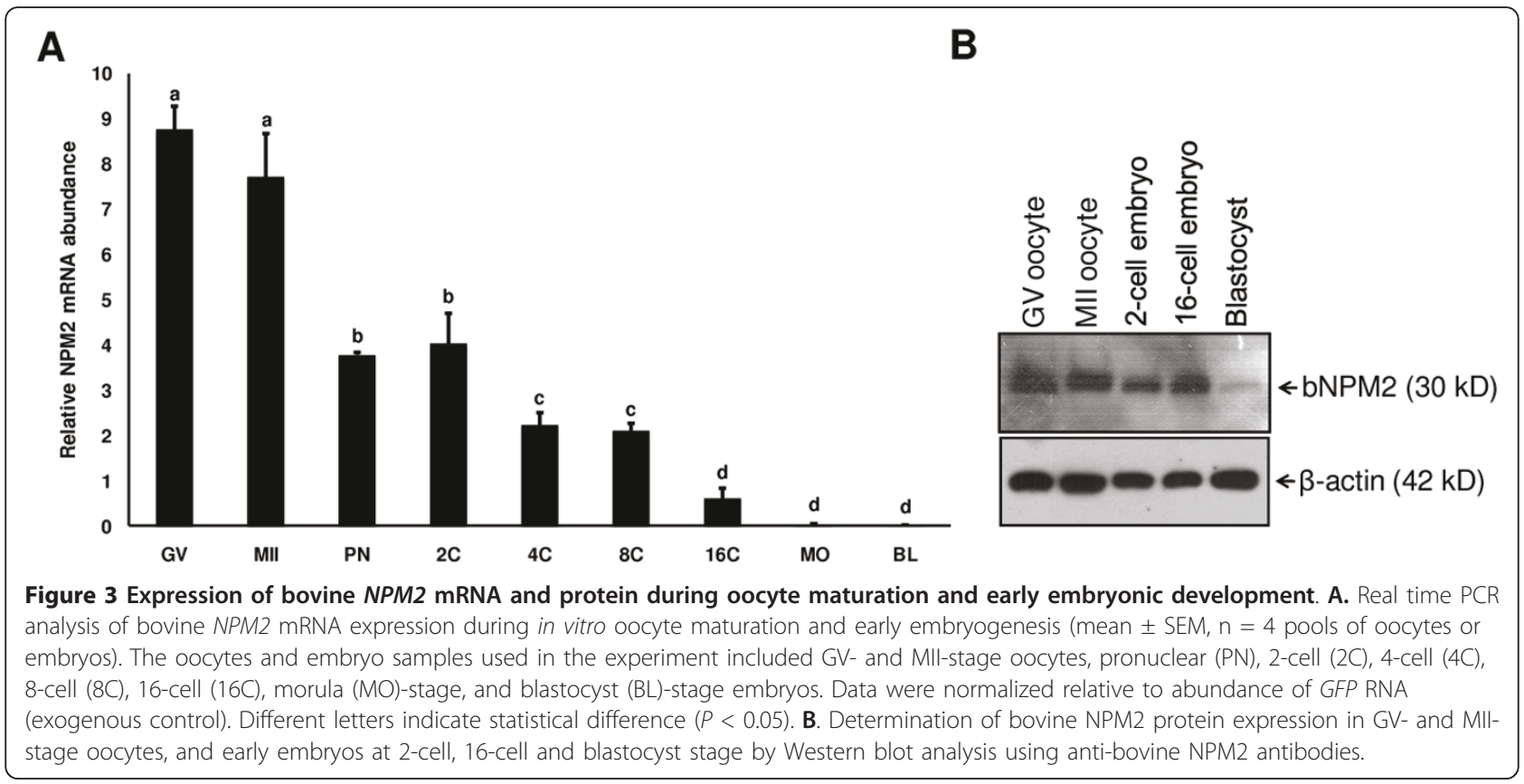


of known bovine maternal effect genes essential for early embryonic development $[18,19,21,22]$ and suggests maternal origin of this factor. Furthermore, NPM2 mRNA abundance in 8-cell embryos was not diminished by culture in the presence of the transcriptional inhibitor alpha-amanitin (data not shown) indicating that the NPM2 mRNA detected in the early bovine embryos is maternal/oocyte derived. Although the NPM2 mRNA was significantly reduced by the 16 -cell stage, the protein level did not decrease until after the 16-cell stage (Figure 3B), indicating that NPM2 may be required for nuclear reorganization in embryos through the time of embryonic genome activation in cattle at the 8- to 16-cell stage [31].

\section{Expression of bovine NPM2 mRNA is decreased in oocytes from persistent follicles}

Results of numerous studies indicate that competence or quality of oocytes harvested from persistent dominant follicles is poor [32,33]. For example, embryos derived from oocytes obtained from persistent dominant follicles underwent embryonic death in vivo by the 16-cell stage [34]. Our previous experiments demonstrated that mRNA abundance for genes (MSY2, PARN and YY1) important for early embryogenesis was significantly lower in oocytes obtained from persistent versus growing dominant follicles [24]. As NPM2 is a key oocytespecific nuclear factor essential for early embryonic development, the relative abundance of bovine NPM2 mRNA in oocytes from growing (day 6) and persistent follicles (day 13) was determined by real time PCR. The results indicate that the level of bovine NPM2 mRNA is significantly lower in oocytes from persistent versus growing dominant follicles $(P<0.05)$ (Figure 4$)$, supporting a potential relationship between NPM2 mRNA abundance and oocyte competence. This result is also consistent with results in rainbow trout where low-quality eggs were shown to have lower levels of NPM2 transcript [35]. It is likely that insufficient oocyte store of NPM2 mRNA results in decreased ability of oocyte to perform sperm chromatin remodeling at fertilization which is essential for early embryogenesis. As the expression of NPM2 is associated with oocyte quality, it could potentially serve as a marker for oocyte developmental competence. The relationship between oocyte quality and NPM2 mRNA abundance merits further investigation in other models of oocyte quality.

\section{Evidence of translational silencing of bovine NPM2 by miR-181a}

Based on the expression pattern of bovine NPM2 mRNA during early embryonic development and recent evidence indicating the involvement of miRNAs in regulation of maternal RNA [15-17], it was hypothesized

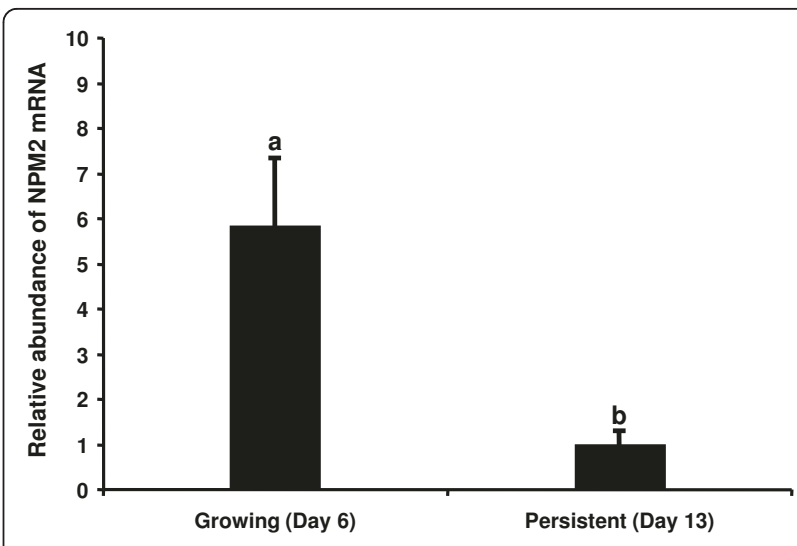

Figure 4 Determination of NPM2 mRNA abundance in oocytes from growing and persistent dominant follicles by quantitative real time PCR analysis (mean $\pm S E M, n=4$ ). Bovine HIST2H2AA4 gene was used as an endogenous control for data normalization. Relative abundance of NPM2 mRNA is significantly lower in oocytes from persistent than from growing follicles. Different letters indicate statistical difference $(P<0.05)$.

that NPM2 might be targeted by miRNAs for silencing and/or degradation during early embryogenesis. Potential miRNA binding sites in the 3'UTR of bovine NPM2 mRNA were predicted using MicroInspector [36], an algorithm for detection of possible interactions between miRNAs and target mRNA sequences [37]. A miR-181a binding site in bovine NPM2 3'UTR was identified (Figure 5A). Alignment of the 3'UTR sequence for bovine NPM2 mRNA with the human and mouse orthologous sequences revealed that the "seed" sequence of the binding site, corresponding to the most important region for miRNA:mRNA interactions, was conserved in all aligned sequences (Figure 5B).

An initial experiment was conducted using real time PCR to determine if miR-181a is expressed in oocytes and early embryos. As shown in Figure 6, miR-181a is present in all stages of oocytes and early embryos examined. There appears to be an increase in miR-181 in oocytes during the transition from GV to MII stage. Following a drop in 2-cell stage embryos, the level of miR$181 \mathrm{a}$ increases again in embryos at 4-cell to 16 cell stage, a period corresponding to the time of embryonic genome activation in cattle when expression of NPM2 decreases gradually. The inverse correlation between miR-181a and NPM2 expression during early embryogenesis further supports our hypothesis that NPM2 might be down-regulated by miR-181a.

To test if miR-181a regulates NPM2 protein expression in the context of its native mRNA sequence, coexpression studies using a construct containing the full length bovine NPM2 cDNA and a plasmid designed to deliver bovine miR-181a were performed. Western blot analysis using antibodies against bovine NPM2 showed 


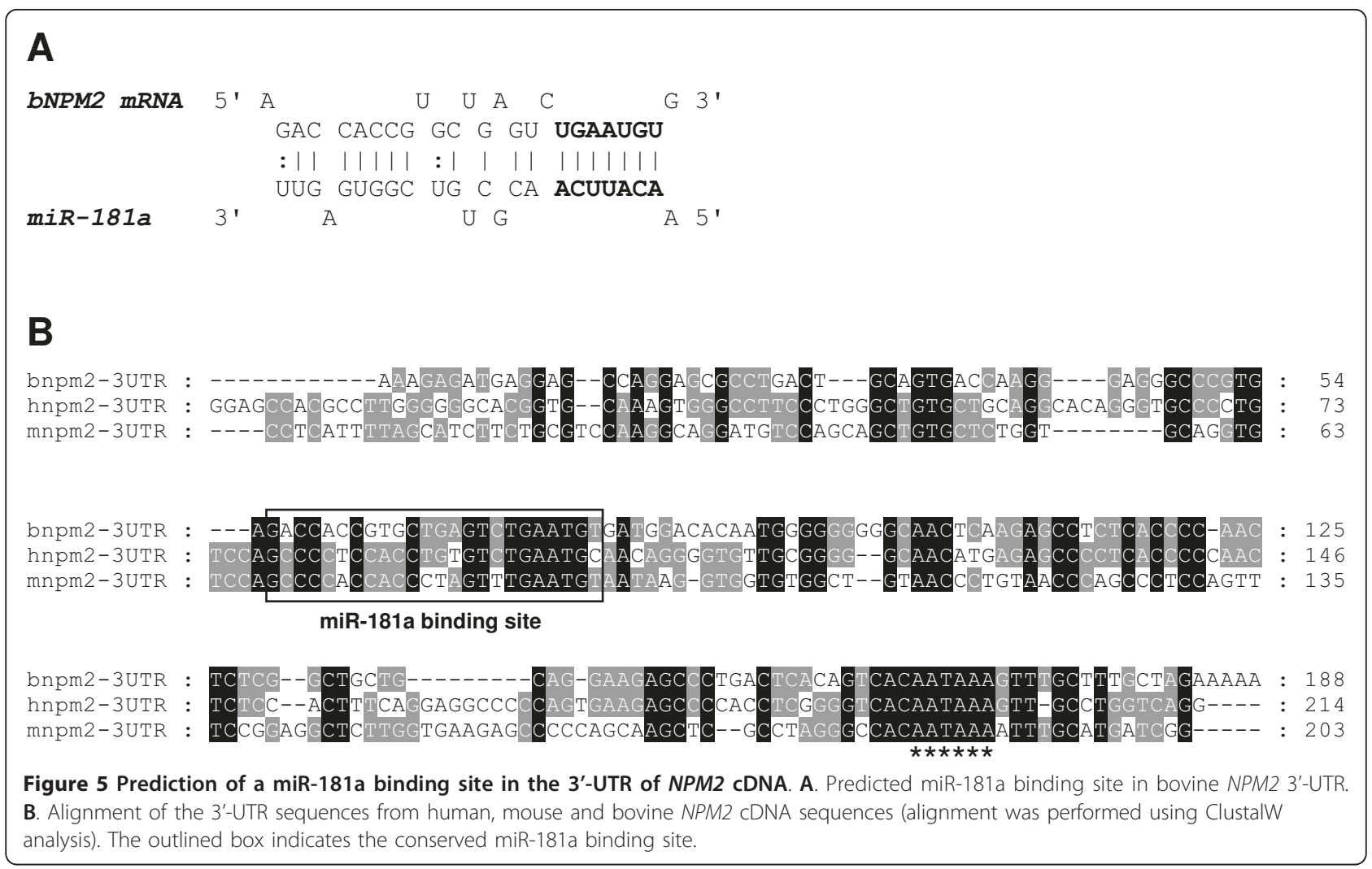

that expression of bovine NPM2 protein was reduced in cells expressing miR-181a compared to control cells without miR-181a (Figure 7A, the minor band present is all samples apparently is a non-specific signal). Quantification of NPM2 protein expression using densitometry (Figure 7B) confirmed that co-expression with miR-181a decreased the level of NPM2 protein

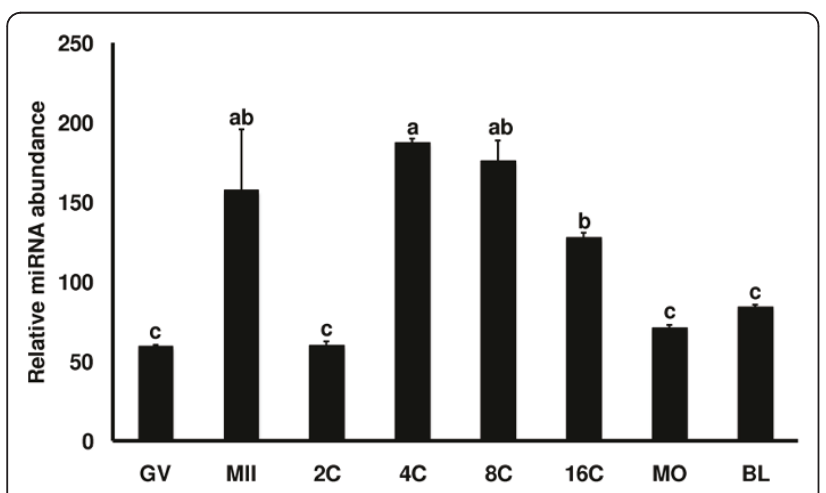

Figure 6 Quantitative real-time PCR analysis of miR-181a expression in oocytes and early embryos (mean $\pm S E M, n=3$ ). The oocytes and embryo samples in the experiment included GVand MII-stage oocytes, 2-cell (2C), 4-cell (4C), 8-cell (8C), 16-cell (16C), morula (MO)-stage, and blastocyst (BL)-stage embryos. Quantity of miR-181a was normalized to miR-125b. Different letters indicate statistical difference $(P<0.05)$.
$(P<0.05)$, indicating that translation of NPM2 is repressed by miR-181a.

miR-181a is a conserved miRNA that has been identified in diverse species. Recent studies have suggested that miR-181a may function as a tumor suppressor in cancer cells [38] or a modulator of cisplatin-induced cancer cell death [39]. It has also been reported that miR-181a down regulates the expression of zinc finger (ZNF) genes by targeting the sequences coding for the ZNF C2H2 domain [40]. The involvement of miR-181a in regulating the expression of NPM2 supports a new role of this miRNA in early embryonic development. Specific miRNAs known to be responsible for maternal mRNA degradation have been reported in zebrafish [17] and Xenopus [41]. However, in mammals, specific miRNAs targeting maternal effect genes have not been reported. This study represents the first report of a specific miRNA potentially involved in regulation of a maternal effect gene in mammalian species.

\section{Conclusions}

Our data suggest that bovine NPM2 present in early embryos is of maternal origin and NPM2 is positively associated with oocyte developmental competence. Results also demonstrate suppression of NPM2 translation by miR-181a and suggest that expression of this 


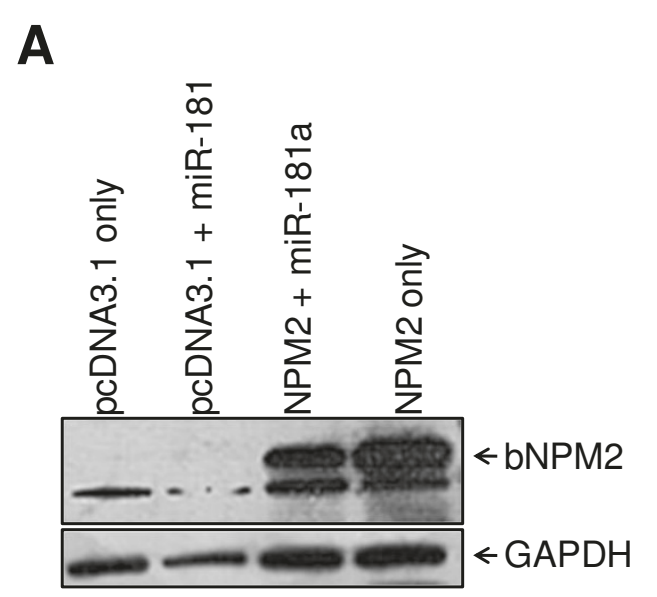

B

Figure 7 Western blot analysis of NPM2 protein expression in Hela cells transfected with NPM2 and miR-181a expression plasmids. A. A representative Western blot showing suppression of NPM2 protein in cells expressing miR-181a. B. Densitometric analysis of protein bands on the Western blots. Data were normalized to GAPDH and expressed as relative pixel density (mean $\pm S E M, n=5$ ). Different letters indicates statistical significance $(P<0.05)$.

essential nuclear factor during early embryogenesis is potentially regulated by miR-181a.

\section{Additional material}

Additional file 1: Table S1: List of primers used in the study.

\section{Acknowledgements}

This project was supported by National Research Initiative competitive grant no. 2008-35203-19094 from the USDA National Institute of Food and Agriculture (GWS), Agriculture and Food Research Initiative competitive grant no. 2009-65203-05706 from the USDA National Institute of Food and Agriculture $(J Y)$ and fund from the West Virginia Agricultural and Forestry Experiment Station (Hatch project No. 427). The study is published with the approval of the station director as scientific paper No. 3093.

\section{Author details}

'Laboratory of Animal Biotechnology and Genomics, Division of Animal and Nutritional Sciences, West Virginia University, Morgantown, WV 26506, USA. ${ }^{2}$ Laboratory of Mammalian Reproductive Biology and Genomics, Michigan State University, East Lansing, Michigan 48824, USA. ${ }^{3}$ Department of Animal Science, Michigan State University, East Lansing, Michigan 48824, USA. ${ }^{4}$ Department of Physiology, Michigan State University, East Lansing, Michigan 48824, USA. ${ }^{5}$ West Virginia School of Osteopathic Medicine, Lewisburg, WV 24901, USA.

\section{Authors' contributions}

BML, SKT and JT performed the experiments. BML drafted the manuscript. GWS and JY designed the study, supervised the experimental work and revised the manuscript. All authors read and approved the final manuscript.

\section{Competing interests}

The authors declare that they have no competing interests.

Received: 16 February 2011 Accepted: 29 March 2011 Published: 29 March 2011

\section{References}

1. Hamatani T, Carter MG, Sharov AA, Ko MS: Dynamics of global gene expression changes during mouse preimplantation development. Dev Cell 2004, 6(1):117-131.

2. Dean J: Oocyte-specific genes regulate follicle formation, fertility and early mouse development. J Reprod Immunol 2002, 53(1-2):171-180.

3. Zheng P, Dean J: Oocyte-specific genes affect folliculogenesis, fertilization, and early development. Seminars in reproductive medicine 2007, 25(4):243-251.

4. Tong ZB, Gold L, Pfeifer KE, Dorward H, Lee E, Bondy CA, Dean J, Nelson LM: Mater, a maternal effect gene required for early embryonic development in mice. Nat Genet 2000, 26(3):267-268.

5. Wu X, Viveiros MM, Eppig JJ, Bai Y, Fitzpatrick SL, Matzuk MM: Zygote arrest 1 (Zar1) is a novel maternal-effect gene critical for the oocyte-toembryo transition. Nat Genet 2003, 33(2):187-191.

6. Burns KH, Viveiros MM, Ren Y, Wang P, DeMayo FJ, Frail DE, Eppig JJ, Matzuk MM: Roles of NPM2 in chromatin and nucleolar organization in oocytes and embryos. Science 2003, 300(5619):633-636.

7. Philpott A, Leno $\mathrm{GH}$ : Nucleoplasmin remodels sperm chromatin in Xenopus egg extracts. Cell 1992, 69(5):759-767.

8. Philpott A, Leno GH, Laskey RA: Sperm decondensation in Xenopus egg cytoplasm is mediated by nucleoplasmin. Cell 1991, 65(4):569-578.

9. Betthauser JM, Pfister-Genskow M, Xu H, Golueke PJ, Lacson JC, Koppang RW, Myers C, Liu B, Hoeschele I, Eilertsen KJ, et al: Nucleoplasmin facilitates reprogramming and in vivo development of bovine nuclear transfer embryos. Mol Reprod Dev 2006, 73(8):977-986.

10. Paynton BV, Rempel $R$, Bachvarova R: Changes in state of adenylation and time course of degradation of maternal mRNAs during oocyte maturation and early embryonic development in the mouse. Dev Biol 1988, 129(2):304-314

11. Schultz RM: Regulation of zygotic gene activation in the mouse. Bioessays 1993, 15(8):531-538.

12. Bettegowda A, Smith GW: Mechanisms of maternal mRNA regulation: implications for mammalian early embryonic development. Front Biosci 2007, 12:3713-3726.

13. Pillai RS: MicroRNA function: multiple mechanisms for a tiny RNA? RNA 2005, 11(12):1753-1761.

14. Bernstein E, Kim SY, Carmell MA, Murchison EP, Alcorn H, Li MZ, Mills AA, Elledge SJ, Anderson KV, Hannon GJ: Dicer is essential for mouse development. Nat Genet 2003, 35(3):215-217. 
15. Tang F, Kaneda M, O'Carroll D, Hajkova P, Barton SC, Sun YA, Lee C, Tarakhovsky A, Lao K, Surani MA: Maternal microRNAs are essential for mouse zygotic development. Genes Dev 2007, 21(6):644-648.

16. Giraldez AJ, Cinalli RM, Glasner ME, Enright AJ, Thomson JM, Baskerville S, Hammond SM, Bartel DP, Schier AF: MicroRNAs regulate brain morphogenesis in zebrafish. Science 2005, 308(5723):833-838.

17. Giraldez AJ, Mishima Y, Rihel J, Grocock RJ, Van Dongen S, Inoue K, Enright AJ, Schier AF: Zebrafish MiR-430 promotes deadenylation and clearance of maternal mRNAs. Science 2006, 312(5770):75-79.

18. Pennetier S, Perreau C, Uzbekova S, Thelie A, Delaleu B, Mermillod P, Dalbies-Tran R: MATER protein expression and intracellular localization throughout folliculogenesis and preimplantation embryo development in the bovine. BMC developmental biology 2006, 6:26.

19. Pennetier S, Uzbekova S, Perreau C, Papillier P, Mermillod P, Dalbies-Tran R: Spatio-temporal expression of the germ cell marker genes MATER, ZAR1, GDF9, BMP15, and VASA in adult bovine tissues, oocytes, and preimplantation embryos. Biol Reprod 2004, 71(4):1359-1366.

20. Brevini TA, Cillo F, Colleoni S, Lazzari G, Galli C, Gandolfi F: Expression pattern of the maternal factor zygote arrest 1 (Zar1) in bovine tissues, oocytes, and embryos. Mol Reprod Dev 2004, 69(4):375-380.

21. Bettegowda A, Yao J, Sen A, Li Q, Lee KB, Kobayashi Y, Patel OV, Coussens PM, Ireland JJ, Smith GW: JY-1, an oocyte-specific gene, regulates granulosa cell function and early embryonic development in cattle. Proc Natl Acad Sci USA 2007, 104(45):17602-17607

22. Tejomurtula J, Lee KB, Tripurani SK, Smith GW, Yao J: Role of importin alpha8, a new member of the importin alpha family of nuclear transport proteins, in early embryonic development in cattle. Biol Reprod 2009, 81(2):333-342.

23. Bettegowda A, Patel OV, Ireland JJ, Smith GW: Quantitative analysis of messenger RNA abundance for ribosomal protein L-15, cyclophilin-A, phosphoglycerokinase, beta-glucuronidase, glyceraldehyde 3-phosphate dehydrogenase, beta-actin, and histone $\mathrm{H} 2 \mathrm{~A}$ during bovine oocyte maturation and early embryogenesis in vitro. Mol Reprod Dev 2006, 73(3):267-278

24. Lingenfelter BM, Dailey RA, Inskeep EK, Vernon MW, Poole DH, Rhinehart JD, Yao J: Changes of maternal transcripts in oocytes from persistent follicles in cattle. Mol Reprod Dev 2007, 74(3):265-272.

25. Tripurani SK, Xiao C, Salem M, Yao J: Cloning and analysis of fetal ovary microRNAs in cattle. Anim Reprod Sci 2010, 120(1-4):16-22.

26. Byrne MJ, Warner CM: MicroRNA expression in preimplantation mouse embryos from Ped gene positive compared to Ped gene negative mice. J Assist Reprod Genet 2008, 25(5):205-214.

27. NCBI Splign. [http://www.ncbi.n/m.nih.gov/sutils/splign/splign.cgi].

28. Yan C, Elvin JA, Lin YN, Hadsell LA, Wang J, DeMayo FJ, Matzuk MM: Regulation of growth differentiation factor 9 expression in oocytes in vivo: a key role of the E-box. Biol Reprod 2006, 74(6):999-1006.

29. Liang L, Soyal SM, Dean J: FIGalpha, a germ cell specific transcription factor involved in the coordinate expression of the zona pellucida genes. Development 1997, 124(24):4939-4947.

30. Vitale AM, Calvert ME, Mallavarapu M, Yurttas P, Perlin J, Herr J, Coonrod S: Proteomic profiling of murine oocyte maturation. Mol Reprod Dev 2007, 74(5):608-616

31. Barnes FL, First NL: Embryonic transcription in in vitro cultured bovine embryos. Mol Reprod Dev 1991, 29(2):117-123.

32. Revah I, Butler WR: Prolonged dominance of follicles and reduced viability of bovine oocytes. J Reprod Fertil 1996, 106(1):39-47.

33. Mihm M, Curran N, Hyttel P, Knight PG, Boland MP, Roche JF: Effect of dominant follicle persistence on follicular fluid oestradiol and inhibin and on oocyte maturation in heifers. J Reprod Fertil 1999, 116(2):293-304

34. Ahmad N, Schrick FN, Butcher RL, Inskeep EK: Effect of persistent follicles on early embryonic losses in beef cows. Biol Reprod 1995, 52(5):1129-1135

35. Aegerter S, Jalabert B, Bobe J: Large scale real-time PCR analysis of mRNA abundance in rainbow trout eggs in relationship with egg quality and post-ovulatory ageing. Mol Reprod Dev 2005, 72(3):377-385.

36. Microlnspector. [http://bioinfo.uni-plovdiv.bg/microinspector/].

37. Rusinov V, Baev $V$, Minkov IN, Tabler M: Microlnspector: a web tool for detection of miRNA binding sites in an RNA sequence. Nucleic Acids Res 2005, , 33 Web Server: W696-700.
38. Shi L, Cheng Z, Zhang J, Li R, Zhao P, Fu Z, You Y: hsa-mir-181a and hsamir-181b function as tumor suppressors in human glioma cells. Brain Res 2008, 1236:185-193.

39. Galluzzi L, Morselli E, Vitale I, Kepp O, Senovilla L, Criollo A, Servant N, Paccard C, Hupe P, Robert T, et al: miR-181a and miR-630 regulate cisplatin-induced cancer cell death. Cancer Res 2010, 70(5):1793-1803.

40. Huang S, Wu S, Ding J, Lin J, Wei L, Gu J, He X: MicroRNA-181a modulates gene expression of zinc finger family members by directly targeting their coding regions. Nucleic Acids Res 2010, 38(20):7211-7218.

41. Lund E, Liu M, Hartley RS, Sheets MD, Dahlberg JE: Deadenylation of maternal mRNAs mediated by miR-427 in Xenopus laevis embryos. RNA 2009, 15(12):2351-2363.

42. ClustalW. [http://www.ebi.ac.uk/Tools/msa/clustalw2/].

doi:10.1186/1477-7827-9-40

Cite this article as: Lingenfelter et al:: Molecular cloning and expression of bovine nucleoplasmin 2 (NPM2): a maternal effect gene regulated by miR-181a. Reproductive Biology and Endocrinology 2011 9:40.

\section{Submit your next manuscript to BioMed Central and take full advantage of:}

- Convenient online submission

- Thorough peer review

- No space constraints or color figure charges

- Immediate publication on acceptance

- Inclusion in PubMed, CAS, Scopus and Google Scholar

- Research which is freely available for redistribution

Submit your manuscript at www.biomedcentral.com/submit
Biomed Central 